\title{
POTENTIOSTATIC ELECTRODEPOSITION OF CUPROUS OXIDE THIN FILMS
}

\author{
L.D.R.D. PERERA ${ }^{1}$, W. SIRIPALA ${ }^{1 *}$ and K.T.L. DE SILVA ${ }^{2}$ \\ ${ }^{1}$ Department of Physics, University of Kelaniya, Kelaniya. \\ ${ }^{2}$ Department of Physics, University of Colombo, Colombo 3.
}

(Received: 20 February 1996; accepted: 06 September 1996)

\begin{abstract}
Current-potential scans were used to investigate the electrodeposition of cuprous oxide thin films in an acetate bath. We found that a narrow potential domain, from O V vS SCE to $-300 \mathrm{mV}$ vs SCE, is available for the potentiostatic electrodeposition of cuprous oxide thin films and extension of this domain towards more cathodic potentials will result in the co-deposition of copper. These results were further verified by the X-ray diffraction measurements on the thin films formed by the electrodeposition at various electrode potentials. Optical transmission studies revealed that electrodeposited cuprous oxide is a direct band gap semiconductor of $2.0 \mathrm{eV}$.
\end{abstract}

Key Words: Cuprous oxide, electrodeposition, thin films

\section{INTRODUCTION}

Electrodeposition is a promising technique that can be used to prepare thin semiconductor films for applications in semiconductor devices. Cuprous oxide is an inexpensive and non -toxic semiconductor material ${ }^{1-4}$ with potential use in low-cost solar energy converting devices. ${ }^{5-8}$ Many reports have been recently published on the electrical, optical and photoelectrochemical properties of electrodeposited cuprous oxide thin films prepared under the gal avanostatic and potentiostatic conditions. ${ }^{2 \cdot 49-11}$ Although the physical properties of the electrodeposited cuprous oxide films were reported, there have been no reports on the electrochemical aspects of the electrodeposition of cuprous oxide thin films. Indeed, such a study is very important for further improvement of the physical properties of the films, as the semiconducting properties of the films can be controlled easily by incorporating impurity atoms during the electrodeposition process. There is particularly the possibility of having better control over the conductivity of cuprous oxide thin films using the electrodeposition method.

In this investigation we have carried out a study on the electrochemical aspects of the electrodeposition of cuprous oxide thin films in an acetate bath, by the method of cyclic voltammetry. We investigated the potential domain where the electrodeposition of cuprous oxide is possible and its dependence on the electrolytic concentration and the temperature of the electrolytic bath. Electrodeposited films were investigated by electrochemical, X-ray diffraction (XRD) and optical absorption methods. 


\section{METHODS AND MATERIALS}

The electrochemical set up used in this investigation is shown in Fig. 1, where the electrochemical cell is kept in a water bath and its temperature is controlled automatically. The counter electrode was a platinum electrode and the reference electrode was a saturated calomel electrode (SCE). Electrolytic solutions were prepared with distilled water and reagent grade chemicals were employed without de-oxygenation. We employed a platinum wire as the working electrode and obtained the voltammetric curves in a bath containing $0.1 \mathrm{M}$ sodium acetate and various concentrations of cupric acetate solutions. A home-made potentiostat and an X-Y recorder were used to obtain the voltammetric curves and the bath solution was stirred continuously using a magnetic stirrer.

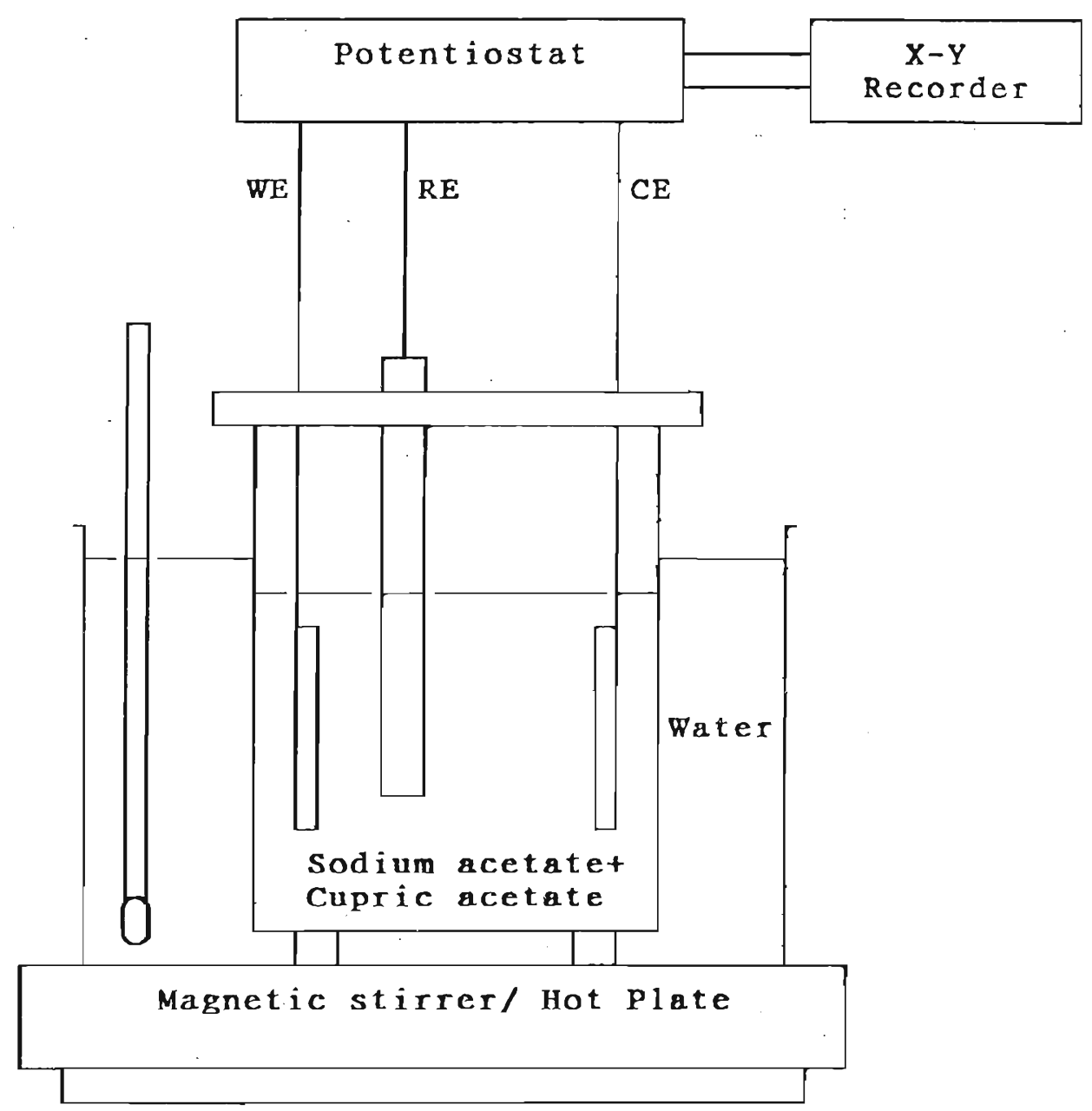

Figure 1: Diagram of the experimental arrangement used for the electrodeposition of cuprous oxide films. 
Thin films were electrodeposited on indium doped tin oxide (ITO) coated glass substrates, in order to characterize the films by optical transmission and XRD methods. Prior to the film deposition substrates were cleaned with a detergent and a dilute aqueous solution of hydrochloric acid, and subsequently rinsed in distilled water. Films were electrodeposited on ITO substrates at various potentials, in the range of $0 \mathrm{~V}$ vs SCE to $-0.6 \mathrm{~V}$ vs SCE, using a bath containing $0.1 \mathrm{M}$ sodium acetate and $1.2 \times 10^{-2} \mathrm{M}$ cupric acetate, at a temperature of $40^{\circ} \mathrm{C}$. XRD measurements were taken with a SHIMADZU (model XD-D1) $\mathrm{X}$-ray diffractrometer and optical transmittance measurements were taken with a HITACHI U-2000 spectrophotometer.

\section{RESULTS}

The current - potential curves obtained with a platinum wire as the working electrode are shown in Fig.2. Curve (a) in Fig. 2 was obtained with a $0.1 \mathrm{M}$ sodium acetate solution while curves $(\mathrm{b})$ to $(\mathrm{g})$ were obtained in solutions containing $0.1 \mathrm{M}$ sodium acetate with the cupric acetate concentrations of $0.05 \times 10^{-2} \mathrm{M}$, $0.1 \times 10^{-2} \mathrm{M}, 0.2 \times 10^{-2} \mathrm{M}, 0.4 \times 10^{-2} \mathrm{M}, 0.8 \times 10^{-2} \mathrm{M}$ and $1.6 \times 10^{-2} \mathrm{M}$, respectively. For all the curves the scan rate was $10 \mathrm{mV} / \mathrm{s}$ and the scans in the cathodic direction were started from their respective rest potentials. It is evident in Fig. 2 that a well defined cathodic wave is developed in the potential range of about $0 \mathrm{~V} \mathrm{vs} \mathrm{SCE}$ to $-300 \mathrm{mV}$ vs SCE due to the presence of cupric ions in the solution, and this wave is developed to a cathodic peak around the potential $0 \mathrm{~V}$ vS SCE at higher cupric acetate concentrations. At the potentials more cathodic to $-300 \mathrm{mV}$ vs SCE, increase in the current with the potential is also observed. Also, we observed that the electrodeposition of films occur at any potential value, starting from $0 \mathrm{~V}$ vs SCE to more cathodic potentials, as we could see them visually by examining the electrode surface.

In the study of the cyclic voltammetric curves we observed two distinct potential regions where the scans in the reversed direction resulted in two different results. Namely, if the cathodic scan was initiated from the rest potential and the potential where it is reversed is in the potential range of $0 \mathrm{~V}$ vs SCE to $-300 \mathrm{mV}$ vs SCE then only two anodic peaks can be observed in the reversed scans. This result is shown in Fig.3(a) where the cupric acetate concentration is $1.0 \times 10^{-2} \mathrm{M}$ : On the other hand, if the potential where the reverse scan starts to go beyond the potential value of $-300 \mathrm{mV}$ vs SCE, an additional anodic peak (AI) is observed at $-150 \mathrm{mV}$ vs SCE. As examples, two cyclic potential scans are shown in Fig.3(b) and Fig.3(b), where the scans were obtained in a cupric acetate concentration of $1.0 \times 10^{-2} \mathrm{M}$. In Fig.3(b), the potential where the reversed scan started is about-550 $\mathrm{mV}$ vs SCE, while in Fig. 3(c), this potential is about $700 \mathrm{mV}$ vs SCE. It is clearly seen in Fig.3(b) and Fig. 3(c), in addition to the anodic peaks AII and AIII an additional anodic peak (AI) is present at the potential around $-100 \mathrm{mV}$ vs SCE, as compared to Fig. 3(a). 


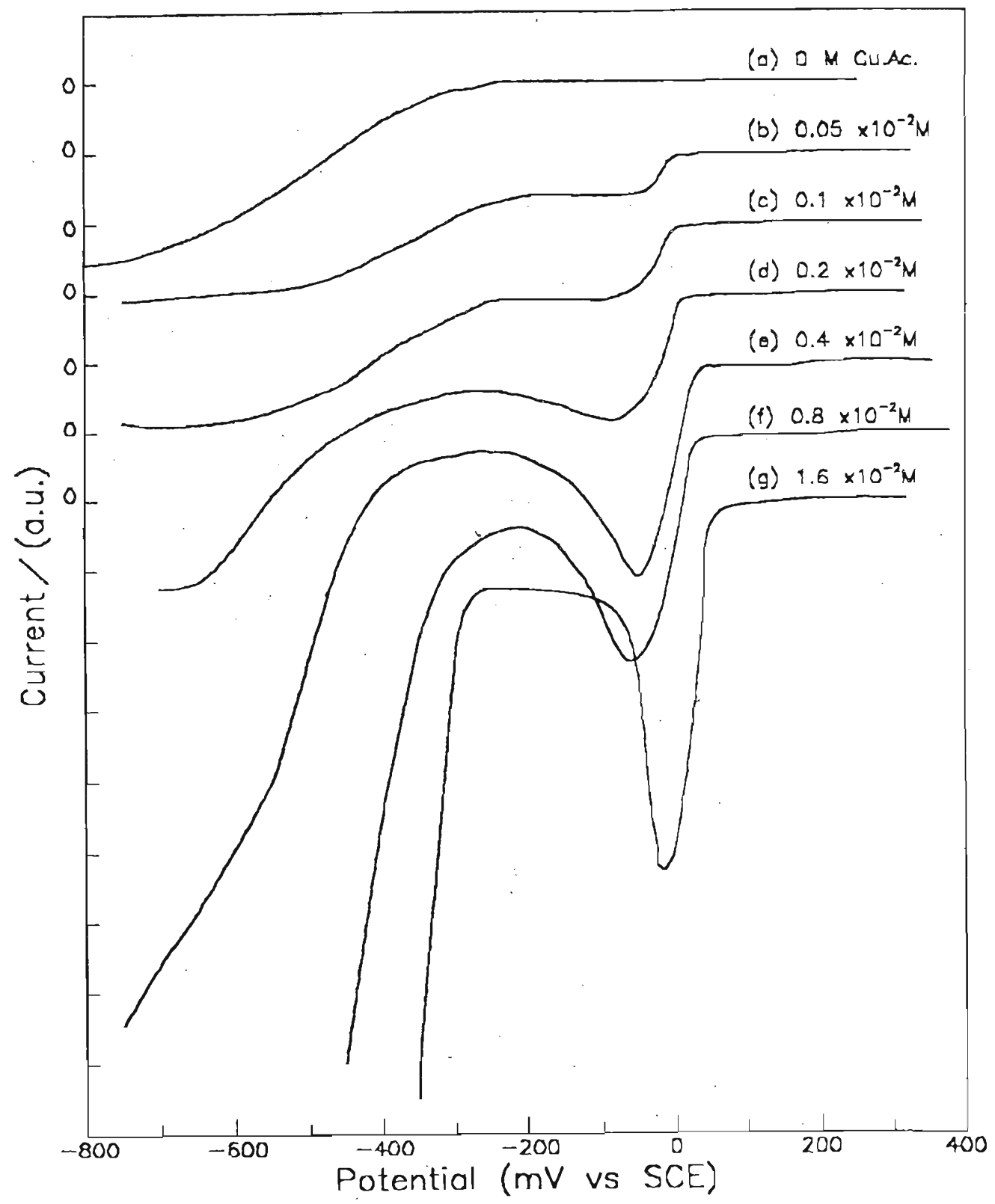

Figure 2: Current - voltage scans of a platinum electrode in an electrochemical cell containing $0.1 \mathrm{M}$ sodium acetate and cupric acetate solutions of concentration; $\begin{array}{llllll}\text { (a) } 0 \text { (b) } 0.05 \times 10^{-2} \mathrm{M} & \text { (c) } 0.1 \times 10^{-2} \mathrm{M} & \text { (d) } 0.2 \times 10^{-2} \mathrm{M} & \text { (e) } 0.4 \times 10^{-2} \mathrm{M} & \text { (f) } 0.8 \times 10^{-2} \mathrm{M}\end{array}$ (g) $1.6 \times 10^{-2} \mathrm{ML}$ 

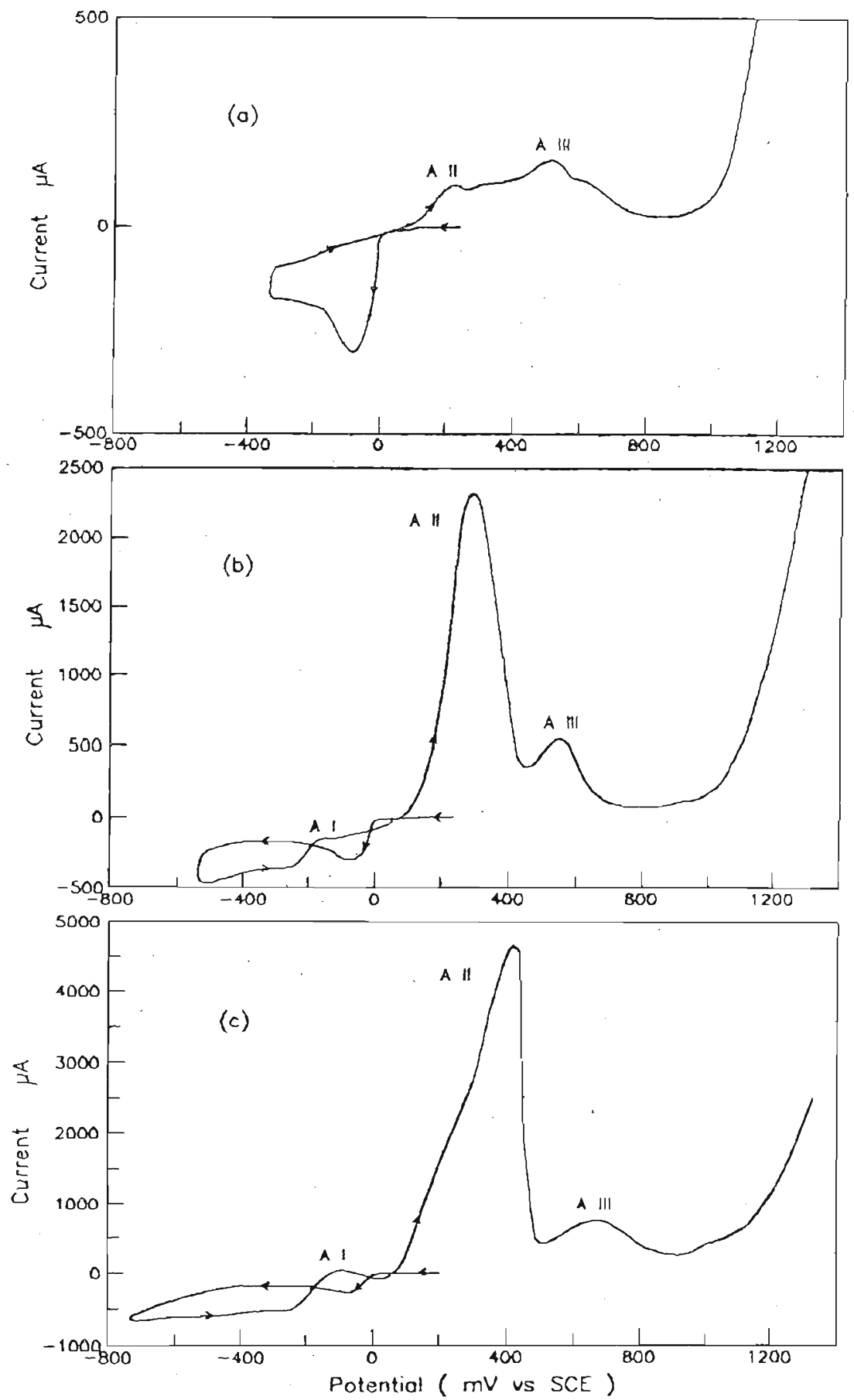

Figure 3: Cyclic voltammetric curves obtained with a platinum wire in a bath containing $0.1 \mathrm{M}$ sodium acetate and $1.0 \times 10^{-2} \mathrm{M}$ cupric acetate solutions. All the scans were initiated at the rest potentials and reversed at the potentials (a) $-300 \mathrm{mV}$ vs SCE (b) $-500 \mathrm{mV}$ vs SCE (c) $-700 \mathrm{mV}$ vs SCE. 
We studied the temperature dependence on the current - potential curves in the temperature range of $30^{\circ} \mathrm{C}$ to $80^{\circ} \mathrm{C}$. Except the general increase of the current with the temperature, we did not observe any significant departure of the qualitative behavior of the current-potential curves, as compared to the curves shown in Figures 2 and 3.

The XRD spectra of the films deposited on ITO substrates at the potentials $-300 \mathrm{mV}$ vs SCE, $-500 \mathrm{mV}$ vs SCE and $-700 \mathrm{mV}$ vs SCE are shown in Fig. 4 . The depositing potential for the film shown in Fig. 4 (a) was selected so that it lies in the potential range of $0 \mathrm{~V}$ vs SCE to $-300 \mathrm{mV}$ vs $\mathrm{SCE}$, the potential range where a plateau is observed in Fig. 2. For the films shown in Fig. 4(b) and Fig.4(c), the depositing potentials were cathodic to $-300 \mathrm{mV}$ vs SCE. It is clearly seen in Fig.4(a) that for the film deposited at potential $-100 \mathrm{mV}$ vs SCE, XRD peaks correspond to cuprous oxide and the ITO substrate are evident. However, for the films deposited at the potentials- $500 \mathrm{mV}$ vs SCE and $-700 \mathrm{mV}$ vs SCE, additional peaks that correspond to $\mathrm{Cu}$ can be observed.

In general, the films grown on ITO substrates were uniform and adhered well to the substrate. The film thickness was estimated by measuring the total charge passed during the film deposition. The long wavelength transmittance spectrum of a film of thickness $2.4 \mu \mathrm{m}$, deposited at $-100 \mathrm{mV}$ vs $\mathrm{SCE}$ on ITO substrate is shown in Fig.5(a). Fig.5(b) shows the determination of the band gap of the film using the data in Fig. 5(a), from the plot of the equation $(\alpha h v)^{2}=A\left(h v-E_{g}\right)$, where $\alpha$ is the absorption coefficient, $E_{g}$ is the band gap and $A$ is a constant. The above equation applies for direct band gap materials and for the optical transmission near the band edge.

\section{DISCUSSION}

It is clearly seen that the electrodeposition of films on the electrode occurs in the entire cathodic potential range we studied here, as it is manifested in Fig. 2 by the increase in the cathodic current due to the presence of cupric ions in the bath solution. The plateau in Fig. 2 corresponds to a particular reaction which produces a certain film on the electrode and the reaction products can be identified easily from the results shown in Figures 3 and 4. As shown in Fig.3, the additional anodic peak (AI) present at the potential - $150 \mathrm{mV}$ vs SCE can be seen only if the reversed scan started at potentials cathodic to $-300 \mathrm{mV}$ vs SCE. Therefore, the origin of this anodic peak must be due to the oxidation of reduced species in the cathodic potentials beyond $-300 \mathrm{mV}$ vs SCE. This anodic peak has been identified previously as due to the oxidation of $\mathrm{Cu}$ to $\mathrm{Cu}_{2} \mathrm{O}$ and therefore $\mathrm{Cu}$ is deposited at more cathodic potentials than $-300 \mathrm{mV}$ vs SCE. ${ }^{12,13}$ The other anodic peaks (AII) and (AIII) are identified as due to the oxidation of $\mathrm{Cu}_{2} \mathrm{O}$ to $\mathrm{CuO}$ and $\mathrm{Cu}(\mathrm{OH})_{2}{ }^{12,13}$ Thus the potentiostatic electrodeposition of cuprous oxide is possible in the potential range between $O \mathrm{~V}$ vs SCE and $-300 \mathrm{mV}$ vs SCE. If the 

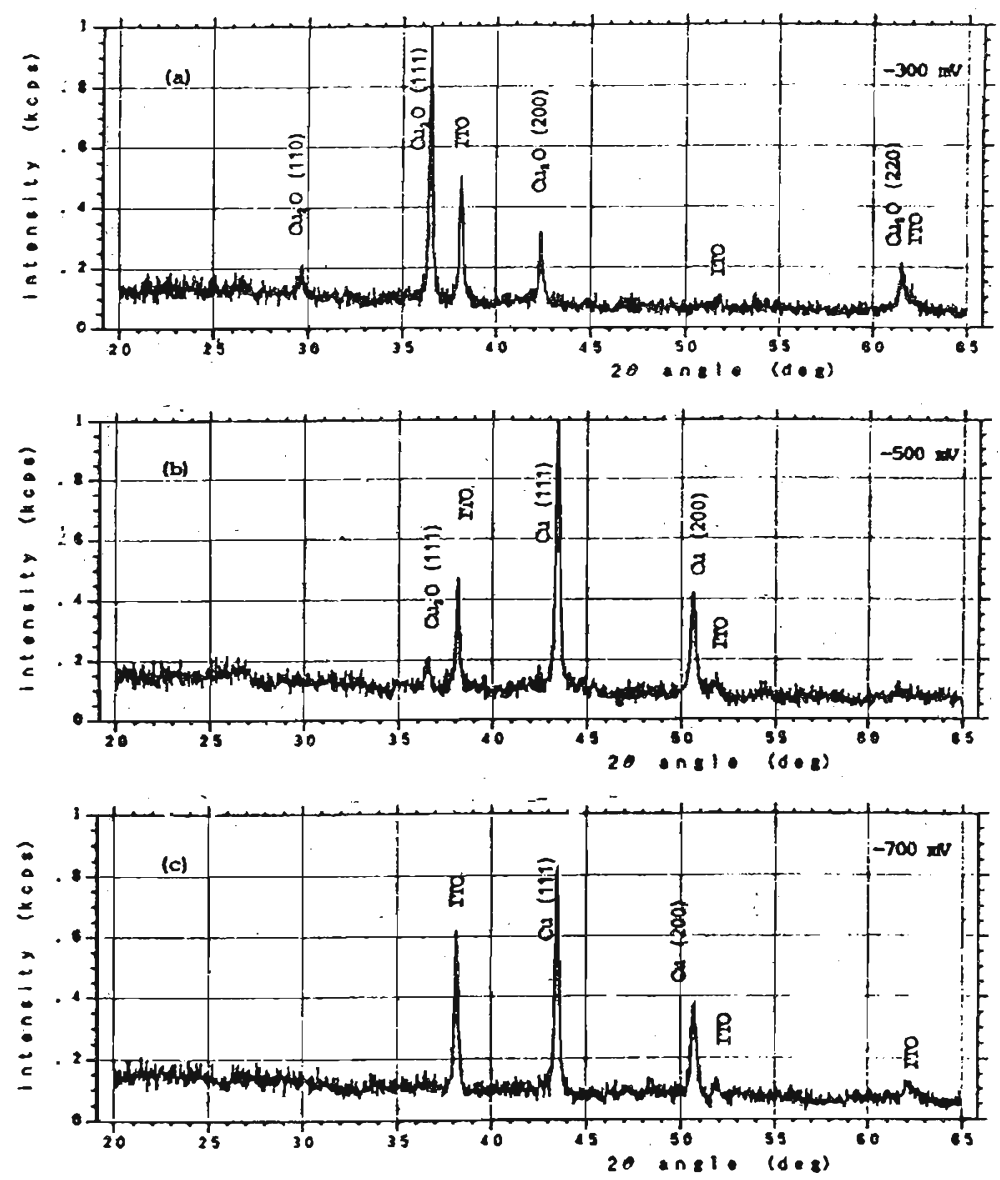

Figure 4: XRD spectra obtained for the films deposited on ITO substrates at the potentials (a) $-300 \mathrm{mV}$ vs SCE (b) $-500 \mathrm{mV}$ vs SCE (c) $-700 \mathrm{mV}$ vs SCE.

depositing potential becomes more negative than $-300 \mathrm{mV}$ vs $\mathrm{SCE}, \mathrm{Cu}$ is codeposited. This is clearly indicated by the hysteresis seen in the I-V curves in Fig.3. This agrees very well with the XRD results shown in Fig. 3, where additional $\mathrm{Cu}$ peaks are evident if the depositing potential exceeds $-300 \mathrm{mV}$ vs SCE. This finding is very important in the electrodeposition of cuprous oxide films because it clearly indicates that electrodeposition of cuprous oxide thin films is possible only within a narrow potential domain of $0 \mathrm{~V}$ vs SCE to $-300 \mathrm{~V}$ vs SCE. Further, our observations reveal that this domain does not depend on the temperature and the concentration of the bath solution.

The electrode reaction which governs the electrodeposition of $\mathrm{Cu}_{2} \mathrm{O}$ is

$$
2 \mathrm{Cu}^{++}+\mathrm{H}_{2} \mathrm{O}+2 \mathrm{e}^{-} \longrightarrow \mathrm{Cu}_{2} \mathrm{O}+2 \mathrm{H}^{+}
$$



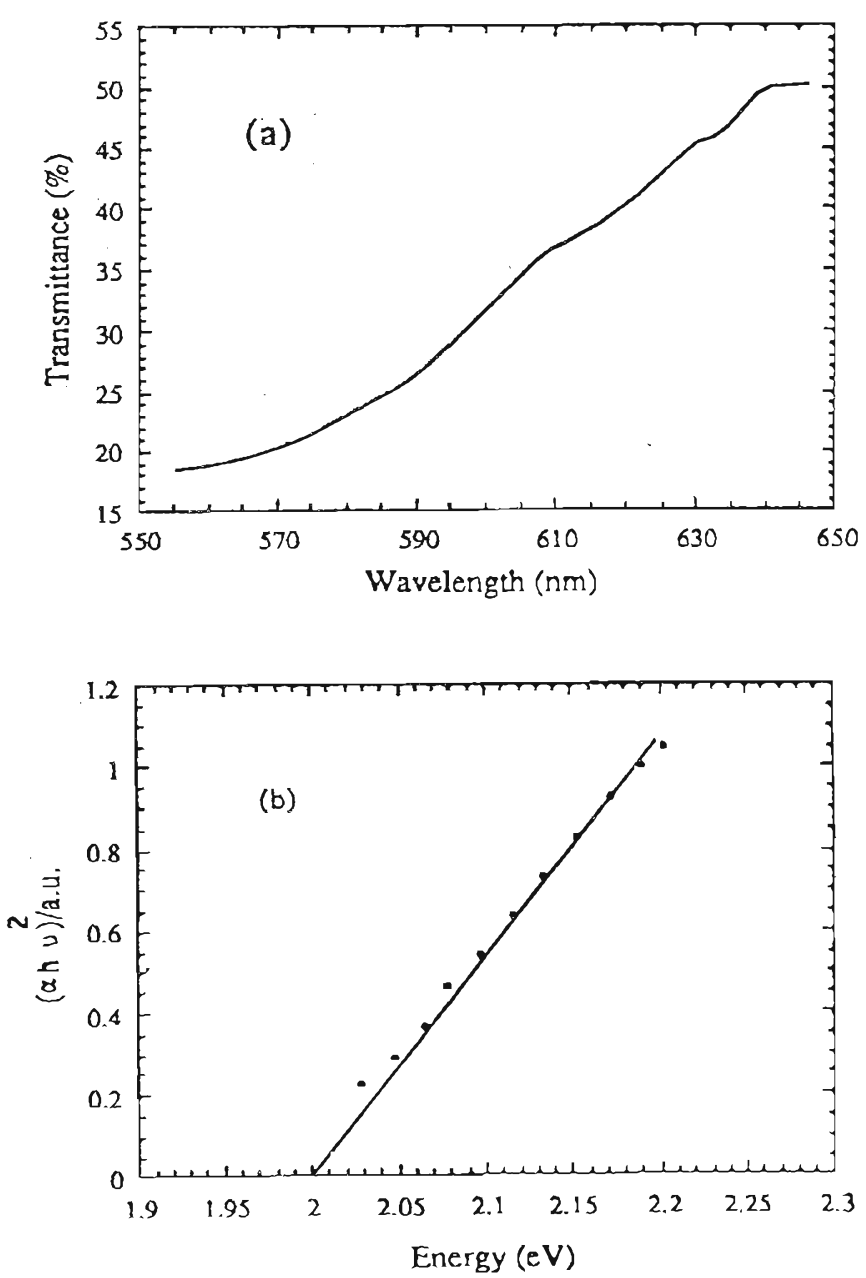

Figure 5: (a) Long wavelength transmission spectrum and (b) $(\alpha h v)^{2}$ vs energy (E) for the cuprous oxide film deposited at $-100 \mathrm{mV}$ vs SCE.

The standard potential for this reaction is $0.203 \mathrm{~V}$ vs NHE and the estimated value of the reaction potential in an acetate bath of $0.4 \times 10^{-2} \mathrm{M}$ cupric ion concentration is about $-0.1 \mathrm{~V}$ vs SCE. This is well within the potential values we found here for the electrodeposition of cuprous oxide films. We measured the thicknesses of the films directly and compared them with the calculated thickness hy knnwing the t $\Omega$ tal charge nassed during the film. deposition. In the calculation we assumed that 2 electrons are consumed for depositing one $\mathrm{Cu}_{2} \mathrm{O}$ molecule and the density of films is the bulk density of single crystals. A very good agreement was obtained between the two methods. Particularly, our result indicates that by monitoring the current we can control the film thickness accurately, as the films are always uniform. The optical 
absorption of films deposited on tin oxide coated substrate clearly shows that the electrodeposited cuprous oxide is a semiconductor having a direct band gap of $2.0 \mathrm{eV}$ which is in very good agreement with the previously reported results.

In conclusion, we have found that the potentiostatic eletrodeposition of cuprous oxide thin films can be carried out in an acetate bath in a potential range of $0 \mathrm{~V}$ vs SCE to $-300 \mathrm{mV}$ vs SCE. Also, we could observe that the extension of the depositing potential towards more cathodic potentials from $-300 \mathrm{mV}$ vs SCE resulted in the co-deposition of copper. Further, it was observed that electrodeposited cuprous oxide is a semiconductor of a direct band gap of $2.0 \mathrm{eV}$.

\section{Acknowledgements}

This work was supported by a grant (RG/94/P/03) from NARESA. WS acknowledges the useful discussions with Drs. J. Vedel and D. Lincot at Laboratoire d'Electrochimie, ENSCP, Paris, France.

\section{References}

1. Economou N.A., Toth R.S., Komp R.J. \& Trivich D. (1977). Photovoltaic cells of electrodeposited cuprous oxide. Proceedings of Europian Communities Photovoltaic Solar Energy Conference, Luxemburg, 1180-1183.

2. Siripala W. \& Jayakody J.R.P. (1986). Observation of n-type photoconductivity in electrodeposited copper oxide film electrodes in a photoelectrochemical cell. Solar Energy Materials 14: 23-27.

3. Rakhshani A.E.,Al-Jassar A.A. \& Varghese J. (1987). Electrodeposition and characrerisation of cuprous oxide. Thin Solid Films 148: 191-201.

4. Chatterjee A.P., Mukhopadhyay A.K., Chakraborty A.K., Sasmal R.N.\& Lahiri S.K. (1991). Electrodeposition and characterisation of cuprous oxide films. Materials Letters 11: 358-362.

5. Olsen L.C., Addis F.W. \& Miller W. (1982). Experimental and theoretical studies of $\mathrm{Cu}_{2} \mathrm{O}$ solar cells. Solar Cells 7: 247-279.

6. Herion J., Niekisch A. \& Scharl G. (1980). Investigation of metal oxide/cuprous oxide heterojunction solar cells. Solar Energy Materials 4: 101-112.

7. Sears W.M. \& Fortin E. (1984). Preparation and properties of $\mathrm{Cu}_{2} \mathrm{O} / \mathrm{Cu}$ photovoltaic solar cells. Solar Energy Materials 10: 93-105.

8. Rai R.P. (1988). $\mathrm{Cu}_{2} \mathrm{O}$ solar cells; a review: Solar Cells 25: 265-272. 
9. Rakhshani A.E. \& Varghese J. (1988). Potentiostatic electrodeposition of cuprous oxide. Thin Solid Films 157: 87-95.

10. Siripala W. \& Kumara K.P. (1989). A photoelectrochemical investigation of the n- and p-type semiconduting behaviour of copper (1) oxide films. Semiconductor Science and Technology 4: 465-468.

11. Siripala W. (1995). Spectral responses of electrodeposited cuprous oxide thin film electrodes. Journal of National Science Council Sri Lanka 23(1): 49-54.

12. Abrantes L.M., Castillo L.M., Norman C. \& Peter L.M. (1984). A photoelectrochemical study of the anodic oxidation of copper in alkaline solution. Journal of Electroanalytical Chemistry 163: 209-221. 